\title{
The Induction of Prostatic Hypertrophy in the Dog
}

\section{with Androstanediol}

\author{
Patrick C. Walsh and Jean D. Wilson \\ From the Department of Internal Medicine, The University of Texas \\ Southwestern Medical School, Dallas, Texas 75235
}

A в S T R A C T The effects of androstanediol and estradiol on prostatic growth were investigated in castrate dogs. Estrogens alone resulted in no significant change in prostatic weight, whereas androstanediol produced growth comparable to that in uncastrated controls. Androstanediol plus estradiol resulted in an even more striking increase in prostate growth. Approximately half the animals receiving androstanediol alone and all of those receiving androstanediol plus estradiol fulfill the weight and histological criteria for prostatic hypertrophy in the dog. Since both of these steroid hormones are presumed to be normal secretory products of the testis, it is possible that they are involved in the pathogenesis of prostatic hypertrophy in the dog.

\section{INTRODUCTION}

Prostatic hypertrophy occurs commonly in only two species, man and dog $(1-4)$. While there are histological differences between the two (3-5), the prostatic hypertrophies in man and dog have many features in common (5-8), suggesting use of the latter as a model for study of pathogenesis. In earlier studies we found a correlation between the rate of dihydrotestosterone ${ }^{1}$ formation and prostatic growth in 11 animal species $(9,10)$. It was also shown that the dihydrotestosterone content of hypertrophic prostates of man and dog was

Dr. Walsh was the recipient of a postdoctoral fellowship under training grant 5 TO1-CA05200. His present address is the Brady Urological Institute, Johns Hopkins Hospital, Baltimore, Md.

Received for publication 29 September 1975 and in revised form 21 January 1976.

1 Abbreviations used in this paper: androstanediol, $5 \alpha$-androstane-3 $\alpha, 17 \beta$-diol ; dihydrotestosterone, $17 \beta$-hydroxy- $5 \alpha$ androstan-3-one; estradiol, 1,3,5(10) estratriene-3,17 $\beta$-diol; estrone, 3-hydroxy-1,3,5(10) estratrien-17-one; testosterone, $17 \beta$-hydroxy-4-androsten-3-one. elevated $(11,12)$, leading to the proposal that unregulated dihydrotestosterone formation might be the cause of the disease. However, treatment of castrate dogs for up to $2 \mathrm{yr}$ with dihydrotestosterone or testosterone failed to induce prostatic hypertrophy, despite attainment of concentrations of the two hormones in the prostate equivalent to those seen in control (noncastrate) dogs that had developed the disorder $(13,14)$.

In view of these results, we decided to test the effects of estradiol and androstanediol on prostatic growth in the dog. Both hormones are normal products of the testes (15). The results to follow indicate that benign prostatic hypertrophy can be produced by the chronic administration of androstanediol, and when estradiol was given in combination with androstanediol, all animals developed hypertrophy.

\section{METHODS}

Two different experimental protocols were followed. In the first two experiments, rectal examination was performed on male mongrel dogs, estimated to be between 1 and $2 \mathrm{yr}$ of age, to exclude the presence of prostatic hypertrophy. The animals were divided randomly into groups and were kept either as control animals or castrated. In the third experiment (Table I), the glands were exposed surgically, three-dimensional measurements (length, width, and depth) were made with calipers, and prostate weight was estimated from the nomogram shown in Fig. 1. The animals were then castrated and divided into groups so that average prostatic weights were comparable.

Intramuscular injections of either $1 \mathrm{ml}$ triolein (control) or triolein containing androgen $(25 \mathrm{mg} / \mathrm{ml})$, estrogen $(0.25 \mathrm{mg} / \mathrm{ml})$, or androgen plus estrogen were given three times weekly for the indicated periods. Total weekly dosage in all instances was $75 \mathrm{mg}$ for androgens and $0.75 \mathrm{mg}$ for estrogens. At 6-mo intervals the animals were subjected to repeat laparotomy for reassessment of prostatic size or

\footnotetext{
${ }^{2}$ Ewing, L., B. Brown, D. C. Irby, and I. Jardine. Testosterone and $5 \alpha$-reduced androgen secretion by rabbit testesepididymes perfused in zitro. Submitted for publication.
} 
TABLE I

Effect of Androstanediol and Androstanediol plus Estradiol on Prostate Weight in the Castrate Dog

\begin{tabular}{|c|c|c|c|c|c|c|c|c|c|}
\hline \multirow[b]{2}{*}{ Group } & \multirow[b]{2}{*}{ Preparation } & \multirow[b]{2}{*}{ Number } & \multirow{2}{*}{$\begin{array}{c}\text { Average } \\
\text { body } \\
\text { wt }\end{array}$} & \multirow[b]{2}{*}{ Treatment } & \multicolumn{4}{|c|}{ Prostate wt } & \multirow{2}{*}{$\begin{array}{l}\text { Number } \\
\text { with } \\
\text { prostates } \\
\text { greater } \\
\text { than } 15 \mathrm{~g} \\
\text { at end }\end{array}$} \\
\hline & & & & & Beginning & $6 \mathrm{mo}$ & $12 \mathrm{mo}$ & change & \\
\hline & & & $k g$ & & $g \pm S E M$ & $g \pm S E M$ & $g \pm S E M$ & $g$ & \\
\hline I & Control & 3 & 18 & Triolein & $5.6 \pm 1.9$ & $9.2 \pm 1.3$ & $12.5 \pm 2.1$ & +6.9 & $1 / 3$ \\
\hline II & Castrate & 5 & 14 & Androstanediol & $4.6 \pm 0.8$ & $14.2 \pm 4.3$ & $14.7 \pm 1.8$ & +10.1 & $2 / 5$ \\
\hline III & Castrate & 5 & 14 & $\begin{array}{l}\text { Dihydrotestosterone } \\
\text { plus estradiol }\end{array}$ & $4.5 \pm 0.7$ & $4.2 \pm 0.9$ & $3.6 \pm 0.3$ & -0.9 & $0 / 5$ \\
\hline IV & Castrate & 5 & 15 & $\begin{array}{l}\text { Androstanediol } \\
\text { plus estradiol }\end{array}$ & $4.6 \pm 0.9$ & $29.5 \pm 8.0$ & $35.8 \pm 1.4$ & +31.2 & $5 / 5$ \\
\hline $\mathrm{V}$ & Castrate & 3 & 22 & $\begin{array}{l}\text { Androstanediol } \\
\text { plus estradiol }\end{array}$ & $17.5 \pm 3.0$ & $56.2 \pm 6.5$ & $56.4 \pm 6.4$ & +38.9 & $3 / 3$ \\
\hline
\end{tabular}

Prostate volume was estimated at the time of exploratory laparotomy in a group of mongrel dogs, and the prostate weights were estimated from the nomogram shown in Fig. 1. The animals were then grouped so that the normal prostates were approximately equal in size (groups I-IV), and a group with early prostatic hypertrophy was identified (group V). Groups II-V were then castrated, and drug regimens were begun consisting either of 1 ml of triolein alone three times a week or the same volume of triolein containing androstanediol or dihydrotestosterone (25 mg three times a week) with or without estradiol $(0.25 \mathrm{mg}$ three times a week). At the end of $6 \mathrm{mo}$, exploratory laparotomy was performed, and the weights were estimated from the threedimensional volumes as before. At the end of $12 \mathrm{mo}$, the animals were killed, and the prostates were removed, weighed, and examined histologically.

killed. At the termination of all experiments, the prostates were removed, cleaned, weighed, and examined histologically.

All steroids were obtained from Steraloids, Inc., Pawling, N. Y.

\section{RESULTS}

In the first studies (results not shown), the effect of 6-mo treatment with estrogen alone or in combination with androgens was assessed in 10 dogs ( 5 groups of 2) in which the initial prostate size was estimated by rectal examination only. Neither estradiol nor estrone

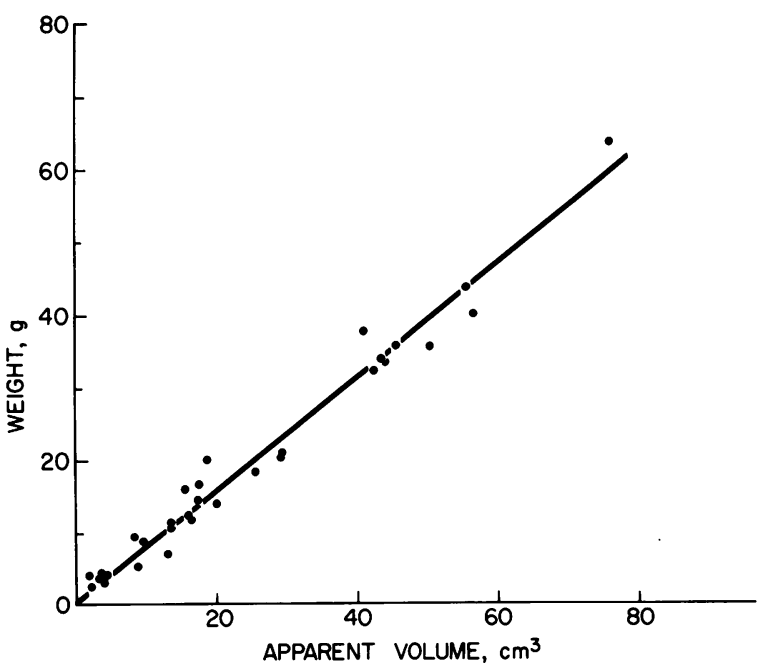

FIGURE 1 Relation between apparent volume and prostatic weight in the dog. For estimation of the apparent volume of the prostate, the gland was exposed surgically in 31 dogs, and measurements obtained with calipers in three dimensions (length, width, and depth) were cubed. The prostates were then removed and weighed directly.

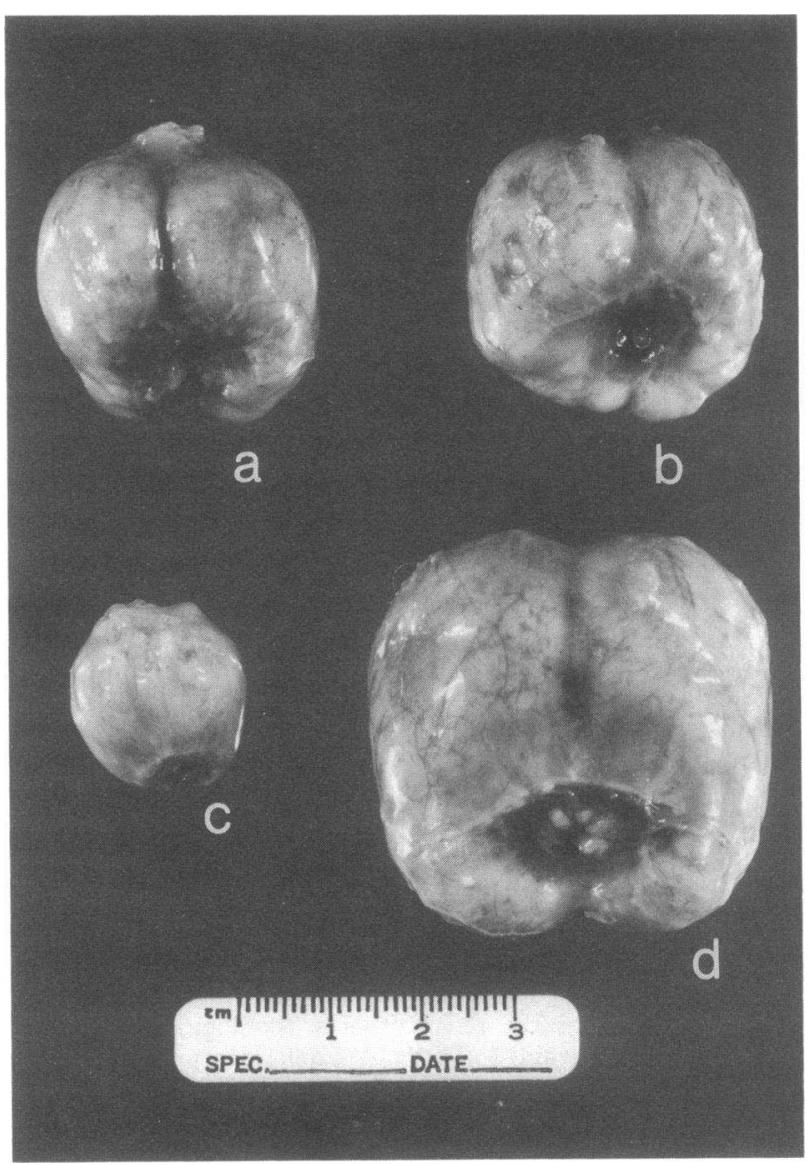

FIGURE 2 Photographs of prostates from dogs treated with various hormonal regimens (Table I). a. Control, hypertrophic prostate, $16.2 \mathrm{~g}$ (group I) ; $b$. castrate given androstanediol, $17.4 \mathrm{~g}$ (group II) ; $c$. castrate given dihydrotestosterone plus estradiol, $4.0 \mathrm{~g}$ (group III) $; d$. castrate given androstanediol plus estradiol, $36.0 \mathrm{~g}$ (group IV). 


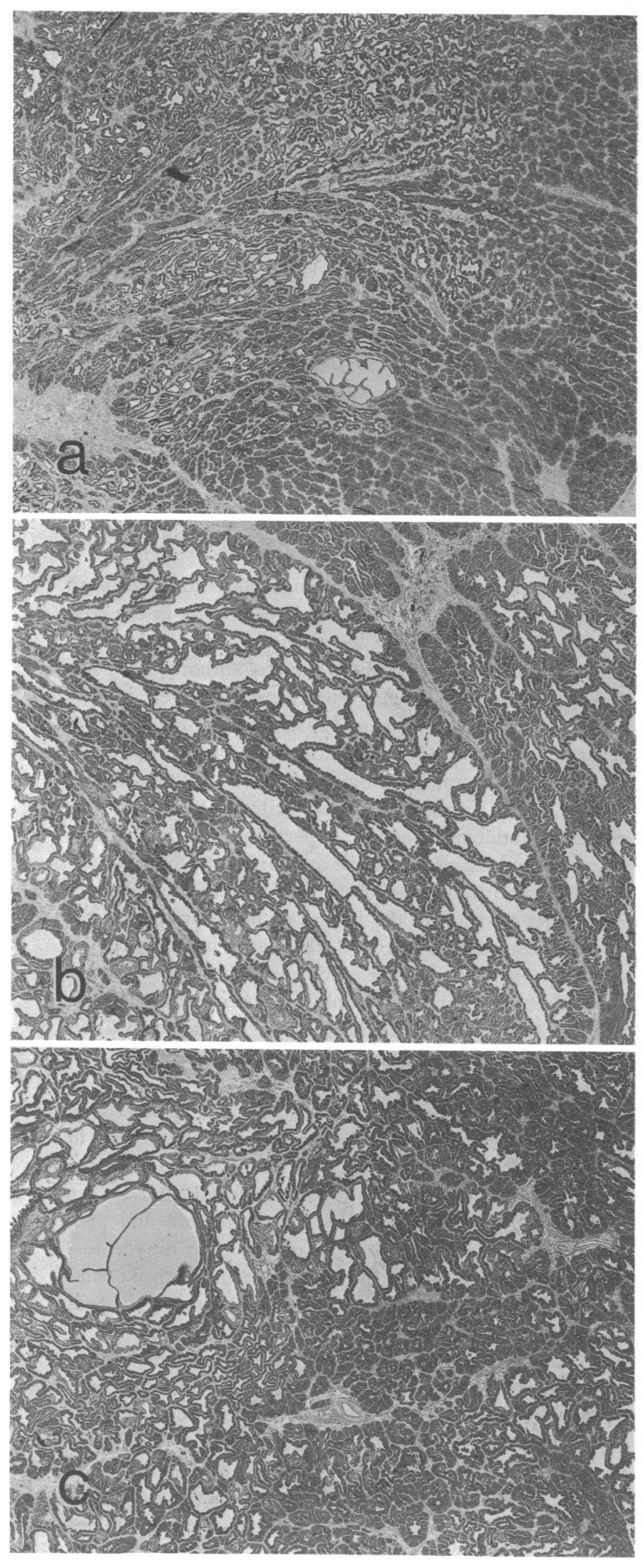

Figure 3 Histological sections of prostates from dogs treated with various

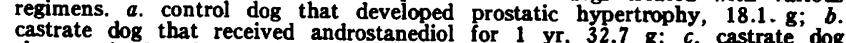
castrate dog that received androstanediol for $1 \mathrm{yr}, 32.7 \mathrm{~g}$; $c$. castrate dog
that received androstanediol for $1 \mathrm{yr}, 15.8 \mathrm{~g} ; \mathrm{d}$. castrate dog given estradio
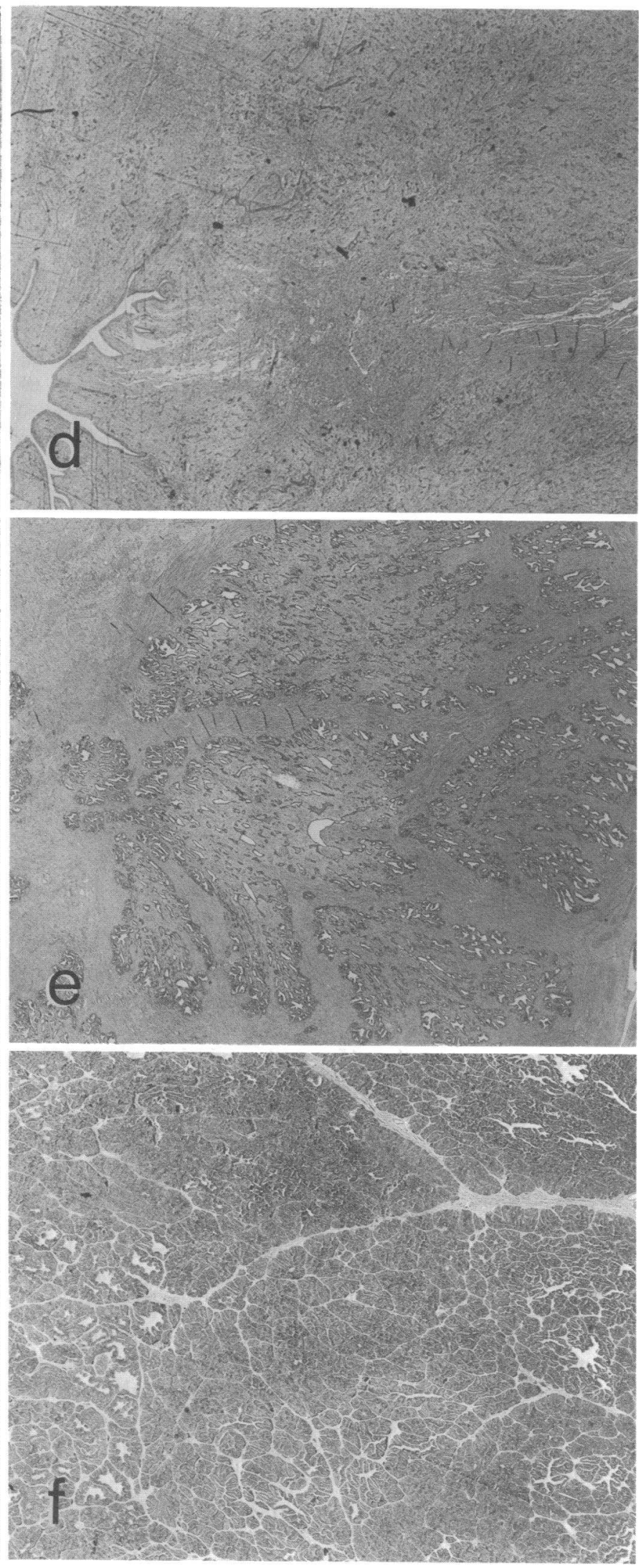

for $6 \mathrm{mo}, 4.2 \mathrm{~g}$; e. castrate dog given dihydrotestosterone plus estradiol for $\frac{1}{\mathrm{yr},} 6.7 \mathrm{~g}$; $f$. castrate dog given estradiol plus androstanediol for $1 \mathrm{yr}$, 
produced significant prostate growth (average weight 4.8 and $3.3 \mathrm{~g}$, respectively) when compared to the average weight in control castrates in this laboratory $(3.3 \mathrm{~g})$. When dihydrotestosterone or testosterone was added to estrone and estradiol at these dosages, the effect was no different from that of the androgens given alone $(13,14)$. Similar studies were carried out with $3 \alpha-$ androstanediol in a second group of 10 dogs. At the end of $6 \mathrm{mo}$, two of four animals treated with androstanediol had prostates greater than $15 \mathrm{~g}$ in weight, and both of two animals treated for $1 \mathrm{yr}$ had profound prostatic enlargement, averaging $24.9 \mathrm{~g}$ in weight. Thus, for the first time, enlargement of the prostate comparable to that seen in natural prostatic hypertrophy had been produced in the castrate animal.

All previous studies were performed on mongrel dogs without quantitative assessment of initial prostate size. To be certain that the prostatic hypertrophy was in fact induced by the treatment and not the result of unsuspected variation in initial prostatic size, a prospective study was devised. First, a nomogram was constructed that allows estimation of prostatic weight from the measurement of three-dimensional volume (Fig. 1). Initial prostatic weights were estimated from the nomogram, and animals with equivalent prostatic weights $(4.5-5.6 \mathrm{~g})$ were either castrated or kept as controls (Table I). The castrates were then given androstanediol (group II), dihydrotestosterone plus estradiol (group III), or androstanediol plus estradiol (group IV). A group of animals found to have early prostatic hypertrophy (average weight of prostate, $17.5 \mathrm{~g}$ ) were castrated and given androstanediol plus estradiol (group V). In all groups, the most significant weight changes occurred within the first 6 mo of the study. Androstanediol treatment resulted in a mean increase in prostatic weight of $10.1 \mathrm{~g}$ in $1 \mathrm{yr}$. Two of five animals had prostates greater than $15 \mathrm{~g}$ at the end of the study (21.1 and $15.8 \mathrm{~g}$, respectively). One of three untreated control dogs also developed an enlarged prostate $(16.2 \mathrm{~g})$. Even more striking results were produced by the combination of androstanediol plus estradiol. In this group the average increase in gland size was $31.2 \mathrm{~g}$; in the five animals the smallest prostate weighed $32.5 \mathrm{~g}$ while the largest was $40.6 \mathrm{~g}$. In contrast, treatment with estradiol plus dihydrotestosterone caused no significant weight change. The findings in the group $\mathrm{V}$ animals, in which androstanediol and estradiol were administered to dogs with initially enlarged prostates, were almost identical to those of group IV. Average weight increase was $38.9 \mathrm{~g}$, and final weights were $43.8,63.9$, and $61.6 \mathrm{~g}$.

Representative photographs of prostates removed from dogs of groups I-IV are shown in Fig. 2. It is clear that androstanediol alone causes growth equivalent to that seen in the control (naturally occurring) hyper- trophy, and that androstanediol plus estradiol produced an even greater increase in size.

The histological features of various prostates from this study are illustrated in Fig. 3. The hypertrophic canine prostate characteristically exhibits microcyst formation in the midst of an active secretory epithelial network, as can be seen clearly in Fig. 3a. Similar changes were seen in two prostates with androstanediolinduced prostatic hypertrophy (Fig. $3 b$ and $3 c$ ). The prostate from the estradiol-treated castrate (Fig. $3 d$ ) contains no demonstrable secretory epithelium and is indistinguishable from that of the untreated castrate (12). Dihydrotestosterone plus estradiol resulted in areas of epithelial differentiation amidst islands of undifferentiated stroma (Fig. 3e), whereas estradiol plus androstanediol caused a striking epithelial hyperplasia (Fig. $3 f)$.

\section{DISCUSSION}

The present experiments were undertaken to develop an experimental model for prostatic hypertrophy in the dog. Criteria for the definition of prostatic hypertrophy have been formulated differently by various authors. Berg has reported that the normal dog prostate never weighs more than $15 \mathrm{~g}(16,17)$, and it has been emphasized by several workers that cystic dilatation of the epithelial acini is a common histological feature of the disorder $(3,7,17)$. According to these criteria, we have succeeded in inducing prostatic hypertrophy in the castrate dog with androstanediol alone and with estradiol in combination with androstanediol. The present findings are in distinct contrast to the failure of testosterone and dihydrotestosterone, alone $(13,14)$ and in combination with estrogen, to induce such growth. The ultimate proof that prostatic hypertrophy has been induced in the castrate dog will require in addition the demonstration that symptomatic urinary or rectal obstruction has been induced.

Considerable additional work is required to determine whether these findings have causal implications as to the etiology of prostatic hypertrophy. Since dihydrotestosterone can be converted to androstanediol in the prostate (18), it is surprising that androstanediol promotes prostatic growth more efficiently than dihydrotestosterone itself. The dog prostate contains both $3 \alpha$ - and $3 \beta$-hydroxysteroid oxidoreductases (18), and it is possible that the unique feature of the $3 \alpha$ (as contrasted to the $3 \beta$ ) androstanediol is that it circumvents the formation of the $3 \beta$ derivative, which does not promote growth of the rat prostate (19). Pharmacological doses of hormones have been utilized in the present study, and it will be necessary to determine whether prostate growth can be induced by physiological doses. Along these lines, it will also be critical to measure the content of these hormones 
in normal and hypertrophic prostates. The possibility that estrogens may play a role in the normal development of the hypertrophic dog prostate deserves careful scrutiny. Such a role was suggested by Zuckerman and Groome in 1937 (20), but in succeeding years it has never been documented clearly that at physiological levels estrogens exert a significant role in prostate growth.

Despite these reservations, the present findings are a promising development in the exploration of the pathogenesis of prostatic hypertrophy. The availability of a convincing experimental model makes it possible to devise experiments to determine whether the pathophysiologic mechanism in susceptible species involves increased concentrations of normal testicular hormones, the production of unique hormone derivatives, or an abnormal androgen receptor-recognition machinery in the prostate itself.

\section{ACKNOWLEDGMENTS}

This work was aided by grant AM03892 from the U. S. Public Health Service.

\section{REFERENCES}

1. Moore, R. A. 1944. Benign hypertrophy and carcinoma of the prostate. Occurrence and experimental production in animals. Surgery (St. Louis). 16: 152-167.

2. Huggins, C. 1945. The physiology of the prostate gland. Physiol. Rev. 25 : 281-295.

3. Huggins, C. 1947. The etiology of benign prostatic hypertrophy. Bull. N. Y. Acad. Med. 23: 696-704.

4. Ofner, P. 1968. Effects and metabolism of hormones in normal and neoplastic prostate tissue. Vitam. Horm. 26: 237-291.

5. O'Shea, J. D. 1962. Studies on the canine prostate gland. I. Factors influencing its size and weight. J. Comp. Pathol. Ther. 72: 321-331.

6. Thomson, R. V., and J. E. Ash. 1954. Benign hyperplasia of the prostate gland. In Urology. M. Campbell, editor. W. B. Saunders Company, Philadelphia, Pa. 1095-1124.
7. Schlotthauer, C. F. 1932 . Observations on the prostate gland of the dog. J. Am. Vet. Med. Assoc. 81: 645-650.

8. Barthwick, R., and C. P. Mackenzie. 1971. The signs and results of treatment of prostatic disease in dogs. Vet. Rec. 89 : 374-384.

9. Gloyna, R. E., and J. D. Wilson. 1969. A comparative study of the conversion of testosterone to $17 \beta$-hydroxy$5 \alpha$-androstan-3-one (dihydrotestosterone) by prostate and epididymis. J. Clin. Endocrinol. Metab. 29: 970-977.

10. Wilson, J. D., and R. E. Gloyna. 1970. The intranuclear metabolism of testosterone in the accessory organs of reproduction. Recent Prog. Horm. Res. 26: 309-336.

11. Siiteri, P. K., and J. D. Wilson. 1970. Dihydrotestosterone in prostatic hypertrophy. I. The formation and content of dihydrotestosterone in the hypertrophic prostate of man. J. Clin. Invest. 49: 1737-1745.

12. Gloyna, R. E., P. K. Siiteri, and J. D. Wilson. 1970. Dihydrotestosterone in prostatic hypertrophy. II. The formation and content of dihydrotestosterone in the hypertrophic canine prostate and the effect of dihydrotestosterone on prostate growth in the dog. J. Clin. Invest. 49: 1746-1753.

13. Wilson, J. D., R. E. Gloyna, and P. K. Siiteri. 1975. Androgen metabolism in the hypertrophic prostate. J. Steroid Biochem. 6: 443-445.

14. Wilson, J. D., P. C. Walsh, and P. K. Siiteri. 1976. Studies on the pathogenesis of benign prostatic hypertrophy in the dog. In press.

15. Kelch, R. P., M. R. Jenner, R. Weinstein, S. L. Kaplan, and M. M. Grumbach. 1972. Estradiol and testosterone secretion by human, simian, and canine testes, in males with hypogonadism, and in male pseudohermaphrodites with the feminizing testis syndrome. J. Clin. Invest. 51: 824-830.

16. Berg, O. A. The normal prostate gland of the dog. 1958. Acta Endocrinol. 27 : 129-139.

17. Berg, O. A. Parenchymatous hypertrophy of the canine prostate gland. 1958. Acta Endocrinol. 27: 140-154.

18. Leav, I., R. F. Morfin, P. Ofner, L. F. Cavazos, and E. B. Leeds. 1971. Estrogen and castration-induced effects on canine prostatic fine structure and $\mathrm{C}_{10}$-steroid metabolism. Endocrinology. 89: 465-483.

19. Moore, R. J., and J. D. Wilson. 1973. The effect of androgenic hormones on the reduced nicotinamide adenine dinucleotide phosphate: $\Delta^{4}-3$-ketosteroid $5 \alpha$-oxidoreductase of rat ventral prostate. Endocrinology. 93: 581-592.

20. Zuckerman, S., and J. R. Groome. 1937. The aetiology of benign enlargement of the prostate in the dog. $J$. Pathol. Bacteriol. 44 : 113-124. 